\title{
DISPOSITIVOS DISCIPLINARES PRODUTORES DE SUBJETIVIDADE NA INSTITUIÇÃO TOTAL ${ }^{1}$
}

Sílvio José Benelli

\begin{abstract}
RESUMO. Neste artigo, estamos desenvolvendo um estudo relativo às instituições totais. Pesquisamos no romance "O Ateneu" de Raul Pompéia quais são os dispositivos disciplinares produtores de subjetividade no contexto institucional. Trata-se de uma análise institucional tomando como campo de pesquisa um caso da literatura, pautada pelos referenciais de Goffman e de Foucault. Goffman diz o que são e como funcionam e indica o que produzem as instituições totais. Foucault, por sua vez, nos revela como são possíveis as instituições disciplinares e quais as razões de sua emergência. A leitura de Goffman a partir das análises de Foucault pode nos proporcionar um enriquecimento fecundo na compreensão dos processos de produção de subjetividade na sociedade contemporânea e, de modo específico, no contexto das instituições totais. Goffman analisa as práticas não-discursivas, ele as articula com grande sutileza, fazendo falar os "detalhes" mais pitorescos e aparentemente insignificantes do cotidiano institucional: percebemos então o plano microfísico das relações intra-institucionais, mergulhando nas diferentes estratégias nas quais o poder se ramifica, circula, domina e produz saberes e sujeitos.
\end{abstract}

Palavras-chave: instituição total, produção de subjetividade, dispositivo.

\section{DISCIPLINARY AGENCIES THAT ARE SUBJECTIVITY PRODUCERS IN THE TOTAL INSTITUTION}

\begin{abstract}
A study about total institution was developed. We have searched into the novel "O Ateneu", by Raul Pompéia, which are the subjectivity disciplinary producer agencies in the institution milieu. It is an institutional analysis taking as a research field a case of literature, ruled by Goffman's and Foucault's works. Goffman demonstrated which the agencies are, how they work and indicated the production of total institutions. Foucault provided a source of understanding of the subjectivity production process into the contemporary society, and, specifically, into the total institution milieu. Goffman analyzed the non-discursive practices, articulating them subtly, and revealing that the bizarre and apparently insignificant "details" of the quotidian institution speak by themselves. It was possible to perceive the microphysics plan of institutional relations, dipping into the different strategies where power spreads itself, circulates, dominates and produces knowledge and subjects.
\end{abstract}

Key words: total institution, subjectivity production, agencies.

\section{O INTERNATO ATENEU COMO INSTITUIÇÃO TOTAL}

Consideramos $O$ Ateneu, romance autobiográfico de Raul Pompéia (1863-1895), escrito em 1888, uma obra digna de análise, pois o internato escolar descrito pelo autor pode ser apreciado como exemplo de uma instituição total (Goffman, 1987) em pleno funcionamento.

Pompéia (1888/1997) rememora sua experiência escolar em termos de julgamento, em que a criança que ainda vive no adulto se levanta como um promotor que vai apresentar o elenco das humilhações e mortificações pelas quais foi obrigado a passar, num esforço de elaborar o passado e acertar suas contas com ele. As experiências traumáticas de internado são apresentadas de modo crítico e ácido, através do narrador-personagem Sérgio (Nunes, 1980; PerroneMoisés, 1988).

É surpreendente quanto a narração de Pompéia (1888/1997) pode ser lida a partir da perspectiva das instituições totais (Freitag, 2001; Perrone-Moisés, 1988). Evidentemente o autor não conhecia a teoria de Goffman (1987), mas pôde experimentar em si mesmo os efeitos desta máquina modeladora da subjetividade. Por isso, vamos tratar o texto do Ateneu como se fosse

\footnotetext{
1 Este artigo é parte da pesquisa de mestrado desenvolvida sob orientação do Dr. Abílio da Costa-Rosa/Unesp-Assis com o apoio da Fapesp.

* Psicólogo e Mestre em Psicologia da Faculdade de Ciências e Letras-UNESP, Assis-SP.
} 
a gravação transcrita de um depoimento do autor. Em vez de parafrasear Pompéia (1888/1997), preferimos lançar mão desse artifício e abusar da transcrição literal. Assim, não perdemos o interessante estilo de Pompéia e temos seu próprio testemunho de como realmente funciona uma instituição total, inclusive nos seus detalhes mais pitorescos e nos claramente produtivos de subjetividade.

As análises de Goffman (1987) são extremamente agudas quando estudam as formas da organização do dispositivo institucional. Se ele não chega a articular uma microfísica do poder no contexto institucional e social, como faz explicitamente Foucault (1982, 1972/1999a, 1975/1999b), isso aparece numa leitura atenta em sua investigação do manicômio, da prisão e do convento. Goffman não pode conceituar o poder como relações de força em guerra, entretanto, é assim que sua análise o revela: produzindo no nível microfísico, exatamente do modo como o poder opera, para além dos limites teóricos e conceituais do autor.

Ao estudar as relações intra-institucionais, ele oscila entre os planos molares e microfísicos: estabelece polaridades de poder e não-poder nas quais, aparentemente, este seria privilégio de um grupo minoritário que infligiria a outro mais numeroso as conseqüências do abuso do poder; mas também apresenta um poder que se estende como uma rede de pontos, relações móveis, resistências, efeitos repressivos, coercitivos e, inclusive, produtivos. Estão explícitas as mais diversas estratégias anônimas de poder (Benelli \& Costa-Rosa, 2002).

Goffman (1987) analisa as práticas nãodiscursivas, o não-dito institucional, mas que é claramente visível (e não oculto) e, portanto, dizível: ele os articula com grande sutileza. Goffman faz falar os "detalhes" (Foucault, 1975/1999b, p. 120) aparentemente insignificantes do cotidiano institucional: percebemos então o plano microfísico das relações intra-institucionais superando a pura e simples dimensão organogramática (molar) e mergulhando nas diferentes estratégias nas quais o poder se ramifica, circula, domina e produz saberes, práticas, subjetividade.

Das práticas não-discursivas emergem concepções do objeto institucional e de quais são os meios e instrumentos utilizados para trabalhá-lo. Normalmente, essa teoria e técnica da prática (pois "na prática a teoria é outra") costumam estar em franca contradição e conflito com o discurso institucional oficial (Goffman, 1987, p. 70).

Goffman (1987) demonstra que há mais coisas em comum entre uma prisão e um convento, um asilo de loucos e um campo de concentração, entre um navio em alto-mar e um internato escolar do que parece à primeira vista. Todos estes estabelecimentos utilizam mecanismos de segregação, estratificação social e modelagem da subjetividade, alternando punições, recompensas e a estratégia de dividir para reinar, que não são necessariamente diferentes das relações de dominação e subjetivação dos processos de poder em vigor em toda e qualquer sociedade. Mas nestes estabelecimentos, os mecanismos produtores de subjetividade são exacerbados, por se tratar de situações extremas. De certa forma, são estabelecimentos específicos e como que purificados, revelando as engrenagens do poder de modo mais explícito e evidente, próprias para a pesquisa em laboratório.

A possibilidade de reduzir a identidade social de um sujeito a um atributo estigmatizante ou a um único e exclusivo papel, que representa a categoria social mais baixa dentro de um grupo fechado, é uma estratégia fundamental descoberta por Goffman (1987) nas comunidades fechadas, que ele denomina de instituições totalitárias.

As análises de Goffman (1987) nos apresentam os procedimentos estruturados para a modelagem subjetiva e formas de repressão específicas que são efetuadas dentro dos muros das instituições totalitárias. Também nos revelam que formas de repressão mais gerais se dão na sociedade de massas, produzindo efeitos sobre indivíduos e categorias sociais inteiras.

\section{DISPOSITIVOS INSTITUCIONAIS}

O dispositivo é uma grade de análise construída por Foucault (1982) para dar conta das conexões entre saber e poder: engloba materiais heterogêneos, o dito e o não-dito: arquitetura, discursos, teorias, técnicas, práticas, regras, etc. A partir desses componentes díspares, podemos estabelecer um conjunto de relações flexíveis, reunindo-as num único aparelho, de modo a isolar um problema específico. Munido dessa ferramenta, é possível demarcar a natureza da relação que pode existir entre esses elementos discursivos e não-discursivos, além de evidenciar a função estratégica do dispositivo, na medida em que responde à articulação entre produção de saber e modos de exercício de poder que são dominantes em cada momento histórico.

Nesse sentido, podemos dizer que o poder disciplinar plasmou na sociedade moderna um dispositivo pedagógico autoritário, implementado em todas as suas minúcias na instituição Ateneu, tal como afirma Foucault: 
Assim é que o hospital-edifício se organiza pouco a pouco como instrumento de ação médica (...) um operador terapêutico. Como a escola-edifício deve ser um operador de adestramento, (...) um aparelho de vigiar (Foucault, 1975/1999b, p. 145).

Foucault (1982, 1984, 1972/1999a, 1975/1999b) demonstrou que as relações poder/saber, consideradas como práticas, realizam simultaneamente tanto a produção de conhecimentos específicos sobre o homem quanto uma produção técnica dele no interior de um determinado conjunto de instituições. É nessa articulação entre saber e poder, na intersecção dessas duas práticas sociais, que se produz o sujeito, pois quando se objetivam certos aspectos do homem é que há possibilidade de se organizar uma manipulação técnica institucionalizada dos indivíduos. E o contrário também se verifica, pois é necessário que haja um conjunto de práticas institucionalizadas de manipulação dos indivíduos como condição para sua objetivação científica. Assim se produzem dispositivos psicológicos e pedagógicos.

A subjetividade (modos de ser, sentir, pensar e agir constitutivos do sujeito em determinado momento histórico) é tecida, no contexto institucional, pela rede de micropoderes que sustenta o fazer cotidiano (institucional), operando efeitos de reconhecimento/desconhecimento dessa ação concreta.

Uma instituição é uma prática social que se repete e se legitima enquanto se repete. As instituições implementadas em organizações e estabelecimentos não apenas realizam - quando realizam - os objetivos oficiais para os quais foram criadas, mas produzem determinada subjetividade. Sujeitos são fundados no interior das práticas, sujeitos ao mesmo tempo constituídos no e constituintes do cotidiano institucional. O pensamento costuma reificar objetos e sujeitos que só existem enquanto se produzem e são produzidos dentro de determinadas práticas institucionais.

A produção de subjetividade remete fundamentalmente ao plano micropolítico, microfísico das relações instituintes e instituídas da formação no contexto institucional. Nesta perspectiva, as relações pedagógicas, terapêuticas, educativas entre a equipe dirigente e alunos internados não se configuram como relações estáticas entre pólos constituídos, mas apresentam-se em permanente constituição e ordenação - plenas de vicissitudes - em constante transformação dos lugares e posições no interior das relações, numa pulverização dos lugares instituídos e instituintes.
Desse modo, não podemos conceber práticas e/ou sujeitos autônomos, pois toda prática é efetivada por relações nas quais se configuram sujeitos. Essa é a principal condição para que as instituições existam concretamente. A solidez institucional residiria nos vínculos entre os sujeitos que as fazem cotidianamente, vínculos invisíveis, microfísicos, que se plasmam em relações instituintes e instituídas no contexto institucional, podendo ser mapeadas a partir das forças e dos poderes moleculares que as permeiam.

A seguir, passaremos a descrever os operadores, os instrumentos técnicos institucionais presentes no colégio Ateneu, utilizados para a produção de subjetividade. Entendemos que os excertos do romance são expressamente analíticos por si mesmos, exemplificando os diversos modos como o poder disciplinar se organiza no estabelecimento, produzindo realidade social: arquitetura, atores sociais, discursos, saberes, técnicas políticas de gerenciamento institucional humano.

\section{OPERADORES NORMALIZADORES CONSTITUINTES DO DISPOSITIVO INSTITUCIONAL PEDAGÓGICO}

\section{O plano arquitetônico}

Pompéia descreve a estrutura física do colégio: tratava-se de um grande conjunto arquitetônico, preparado para funcionar como moradia coletiva para crianças e adolescentes, um internato escolar. $\mathrm{O}$ estabelecimento era mantido pelo pagamento de mensalidades pelas famílias dos alunos ali internados, aparecendo como uma empresa privada cuja mercadoria era a educação escolar. A primeira característica totalitária do Ateneu é operar por subtração, utilizando a técnica da seqüestração e do enclaustramento: privação da liberdade, incidindo diretamente sobre o corpo dos educandos. A autonomia pessoal é suprimida pela imposição de uma autoridade onipotente.

O Ateneu estava situado no Rio Comprido, extremo ao chegar aos morros. As eminências de sombria pedra e a vegetação selvática debruçavam sobre o edifício um crepúsculo de melancolia, resistente ao próprio sol a pino dos meios-dias de novembro. Esta melancolia era um plágio ao detestável pavor monacal de outra casa de educação, o negro Caraça de Minas. Aristarco dava-se palmas desta tristeza aérea - a atmosfera moral da meditação e do estudo, definia, escolhida a dedo para maior 
luxo da casa, como um apêndice mínimo da arquitetura (Pompéia, 1888/1997, p. 36).

Quando Sérgio, acompanhado por seu pai, chegou ao colégio para se matricular e ingressar como internado na instituição, o diretor levou-os para a "sala especial das visitas" (Pompéia, 1888/1997, p. 46). Embora o autor não descreva essa sala, ela provavelmente não ficaria distante de um operador que Goffman (1987, p. 91) descreve como parte do cerimonial institucional. Nessa mesma ocasião, Aristarco exibiu o colégio para Sérgio e seu pai (Pompéia, 1888/1997, p. 46-47). Pompéia descreve outros aspectos físicos da instituição: o grande refeitório coletivo (Pompéia, 1888/1997, p. 47), a rouparia anexa ao lavatório, com centenas de bacias e, ao longo das paredes e pouco acima, num friso de madeira, os copos e as escovas de dente (Pompéia, 1888/1997, p. 52). Prossegue ainda desenhando o estabelecimento:

A sala do professor Mânlio era ao nível do pátio, em pavilhão independente do edifício principal, com duas outras do curso primário, o alojamento da banda de música e o salão suplementar de recreio, vantajoso nos dias de chuva. Formando ângulo reto com esta casa, uma extensa construção de tijolo e tábuas pintadas, sala geral do estudo no pavimento térreo e dormitório em cima, concorria para fechar metade do quadrilátero do pátio, que o grande edifício completava, estendendo-se em duas alas, como os braços da reclusão severa. No fundo desta caixa desmedida de paredes, dilatava-se um areal claro, estéril, insípido como a alegria obrigatória, algumas árvores de cambucá mostravam, em roda, a folhagem fixa, com o verdor morto das palmas de igrejas, alourada a esmo da senilidade dos ramos que sofrem, como se não coubesse a vegetação no internato; a um canto, esgalgado cipreste subia até as goteiras, tentando fugir pelos telhados (Pompéia, 1888/1997, p. 55).

Natação chama-se o banheiro, construído num terreno das dependências do Ateneu, vasta toalha d'água ao rés da terra, trinta metros sobre cinco, com escoamento para o Rio Comprido, e alimentada por grandes torneiras de chave livre. O fundo, invisível, de ladrilho, oferecia uma inclinação, baixando gradualmente de um extremo para outro. Acusava-se mais ainda esta diferença de profundidade por dois degraus convenientemente dispostos para que tomassem pé as crianças como rapazes desenvolvidos. Em certo ponto a água cobria um homem. Ao longo do tanque, corria o muro divisório, além do qual ficava a chácara do diretor. À distância, viam-se as janelas de uma parte da casa, onde às vezes eram recolhidos os estudantes enfermos, fechadas sempre as venezianas verdes (Pompéia, $1888 / 1997$, p. 59-60).

(...) A cozinha do Ateneu, além dos alojamentos da copa, era espaçosa como um salão. Às paredes cintilavam o trem completo de cobre areado, em linha as peças redondas como uma galeria de broquéis. No centro uma comprida mesa servia de refeitório à criadagem (Pompéia, 1888/1997, p. 105).

Os dormitórios apelidavam-se poeticamente, segundo a decoração das paredes: salão pérola, o das crianças policiado por uma velha, mirrada e má, que erigira o beliscão em preceito único disciplinar, olhos mínimos, chispando, boca sumida entre o nariz e o queixo, garganta escarlate, uma população de verrugas, cabeça penugenta de gipaeta sobre um corpo de bruxa; salão azul, amarelo, verde, salão floresta, dos ramos do papel, aos quais se recolhia a classe inumerável dos médios. O salão dos grandes, independentes do edifício, sobre o estudo geral, conhecia-se pela denominação amena de chalé. O chalé fazia vida separada e misteriosa (Pompéia, 1888/1997, p. 139).

No Ateneu havia também uma prisão, chamada "cafua", que Sérgio descreve como um "asilo de trevas e do soluço, sanção das culpas enormes" (Pompéia, 1888/1997, p. 74-75). Trata-se de uma espécie de "solitária", lugar onde ficavam detidos os infratores da ordem institucional. A prisão se localizava

embaixo da casa. Fazia-se entrada pelo saguão cimentado dos lavatórios; sentia-se uma impressão de escuro absoluto; para os lados, à distância, brilhavam vivamente, como olhos brancos, alguns respiradouros gradeados daquela espécie de imensa adega. $O$ chão era de terra batida, mal enxuta. Impressionava logo um cheiro úmido de cogumelos pisados. Com a meia claridade dos respiradouros, habituando-se a vista, distinguia-se no meio uma espécie de gaiola ou capoeira de travessões fortes de pinho. Dentro da gaiola um banco e uma tábua pregada, por mesa. Sobre a mesa um tinteiro de barro. Era a cafua (Pompéia, 1888/1997, p. 191). 
O Ateneu é um microcosmo, um rico e complexo universo institucional. Os alunos internados são trezentos meninos e adolescentes. Há toda uma organização de lugares sociais, postos de comando, hierarquia, poder vigilante e normatizador. A equipe dirigente é formada pelo diretor, professores, inspetores e bedéis.

\section{PLANO PSICOSSOCIAL: AS RELAÇÕES INTRA- INSTITUCIONAIS}

\section{O mundo dos alunos internados}

De acordo com Goffman (1987, p. 99-100), o grupo dos internados numa instituição total não deve ser considerado de modo homogêneo. No Ateneu, existem várias diferenças intragrupais: os alunos podem ser divididos entre vigilantes e vigiados (Pompéia, 1888/1997, p. 61-62), efeminados e másculos (Pompéia, 1888/1997, p. 53; 183-184), fortes e fracos, belos e feios, angelicais e pervertidos, leais e traiçoeiros, bolsistas (Pompéia, 1888/1997, p. 147) e pagantes.

$\mathrm{Na}$ descrição que Rebelo faz dos colegas internados para Sérgio, podemos apreciar a divisão sexual que se produzia num colégio unissexual:

'Conte como uma desgraça ter que viver com esta gente' - E esbeiçou um lábio sarcástico para os rapazes que passavam. - 'Aí vão as carinhas sonsas, generosa mocidade... Uns perversos. Têm mais pecados na consciência que um confessor no ouvido; uma mentira em cada dente, um vício em cada polegada de pele. Fiem-se neles. São servis, traidores, brutais, adulões. Vão juntos. Pensa-se que são amigos... Sócios de bandalheira! Fuja deles. Fuja deles. Cheiram a corrupção, empestam de longe. Corja de hipócritas! Imorais! Cada dia de vida tem-lhes vergonha da véspera. Mas você é criança; não digo tudo o que vale a generosa mocidade. Com eles mesmos há de aprender o que são... Aquele é o Malheiro... forte como um touro, todos o temem, muitos o cercam, os inspetores não podem com ele; o diretor respeita-o; faz-se vista larga para os seus abusos (...) Este que passou por nós, olhando muito, é o Cândido, com aqueles modos de mulher, aquele arzinho de quem saiu da cama, com preguiça nos olhos... ali vem o Ribas... feio, coitadinho! Como tudo, mas uma pérola. É a mansidão em pessoa. Primeira voz do Orfeão, uma vozinha de moça que o diretor adora. É estudioso e protegido. Faz a vida cantando como os serafins. Uma pérola ... hoje é o primeiro dia, ali está de joelhos o Franco. Assim atravessa as semanas, os meses, assim o conheço nesta casa, desde que entrei. De joelhos espiando a culpa de uma raça. O diretor chama-lhe de cão, diz que tem calos na cara... Viu aquele da frente, que gritou calouro? Se um dissesse o que se conta dele... aqueles olhinhos úmidos de Senhora das Dores...Isto é uma multidão; é preciso força de cotovelos para romper... Os gênios fazem aqui dois sexos, como se fosse uma escola mista. Os rapazes tímidos, ingênuos, sem sangue, são brandamente impelidos para o sexo da fraqueza, são dominados, festejados, pervertidos como meninas ao desamparo...' (Pompéia, 1888/1997, p. 53-54).

Sérgio, quando passou para o chalé, dormitório coletivo onde se alojam os maiores, descreveu a diversidade da população do colégio:

Depois disso, vinha a demografia especial da terceira classe, a distribuição por famílias regulares, ou por aproximações eventuais... Louvavam-se os exemplos de fidelidade; comentavam-se as traições; censuravam-se as tentativas de sedução; improvisava-se a teoria do lar e do leito; cantava-se o hino báquico dos caprichos volantes, do entusiasmo passageiro. Chamavam-me o Sérgio do Alves. Fazia-se a crítica dos novos sob um ponto de vista inteiramente deles. Apostavam a ver quem seria o primeiro, exigiam juramento de segredo, para passar adiante alguma história que tinham por sua vez jurado não contar a ninguém. Serviam-se mutuamente em pasto às boas risadas, anedotas espessas, com ou sem aplicação, conforme o pedido e o paladar do ensejo. Toda crônica obscura do Ateneu redigia-se ali, em termos explícitos e fortes, expurgada dos arrebiques de recato, de inverdade, pelo escrúpulo das comissões investigadoras. O Silvino que se fosse! Não tinha nada com a conversa dos rapazes. Uma das melhores máximas do chalé era esta, característica: Fica revogado o diretor. Havia o que afetava moderação no capricho, conhecendo o desvio em regra, como o ladrão sabe ser honesto no roubo; com o ar sério, espantadiço das femmes qui sortent; havia os ingênuos, perpetuamente infantis, não fazendo por mal, risonhos de riso solto, com o segredo de adiar a inocência intata através dos positivos extremos, apregoando-se por gosto, que não perdoavam à natureza o erro original da conformação: ah! Não ser eu mulher para melhor o ser! Estes faziam grupo à parte, 
conhecidos e satisfeitos com isto, protegidos por um favor de simpatia geral, inconfessado mas evidente, beneplácito perverso e amável de tolerância que favoneia sempre a corrupção como um aplauso. Eles, os belos efebos! exemplos da graça juvenil e da nobreza da linha. Às vezes traziam pulseiras; ao banho triunfavam, nus, demorando atitudes de ninfa, à beira d'água, em meio da coleção mesquinha de esqueletos sem carnes nas tangas de meia, e carnes sem forma. Havia os decaídos, portadores miseráveis de desprezo honesto, culpados por todos os outros, gastos às vezes antes do consumo, atormentados pela propensão de um lado, pela repulsa de outro, mendigos de compaixão sem esmola, reduzidos ao extremo de conformar-se deploravelmente com a solidão. Com estes em contraposição, os de orgulho masculino, peludos, morenos, nodosos de músculos, largos de ossada, e outros mirrados de malícia, insaciáveis de voz trêmula e narinas ávidas de bode, os gorduchos de beiço vermelho relaxado, fazendo praça de uma superioridade porque nem sempre zelaram antes da madureza das banhas (Pompéia, 1888/1997, p. 183-184).

No plano social no Ateneu, bem distante dos ideais propostos pelo regulamento, os critérios decisivos eram, em primeiro lugar, a força, em segundo, o prestígio da riqueza, que de fora vinha precisar os contornos das diferenças individuais. No plano afetivo, as matrizes dos gestos e das palavras eram a agressividade e a libido. Para observá-lo, basta ler a descrição da fauna que rodeia Sérgio: destruída a fachada que a cerimônia inicial levantara, o menino percebeu espantado uma divisão entre fortes e fracos, que os impulsos da puberdade vinha colorir de matizes sexuais. As lideranças, já entronadas pelo poder da riqueza, se erguiam sobre argumentos musculares ou etários, onde os mais fortes, os mais velhos e calejados pela vida no colégio interno, podem dominar, oprimir e explorar os recém-chegados mais novos. "Tudo conspira contra os indefesos" (Pompéia, 1888/1997, p. 63).

É um universo em que não há arestas, sequer humanidade. A força de um só encontra paralelo no poder de outro. Um equilíbrio pelo temor. É todo um complexo social que se faz presente, onde estes adolescentes são transformados em pequenas feras a fazerem parte de uma estranha matilha que se autodevora. Não há lugar para os puros (como Sérgio), para os fracos (como Franco). Num mundo assim concebido, a fraternidade passa a ser um indício de fraqueza. (Nunes, 1980, p. 228).

\section{SISTEMA DE PRIVILÉGIOS: PUNIÇÕES E PREMIAÇÕES NORMALIZADORAS}

Podemos verificar no modo de funcionamento do Ateneu alguns elementos que consideramos como parte do sistema de privilégios (Goffman, 1987, p. 4958) que costuma existir nas instituições totais. São três os elementos básicos desse sistema: primeiro, um conjunto relativamente explícito e formal de prescrições e proibições que normatizam a conduta do internado. Essas regras costumam especificar com detalhes a rotina diária e austera da vida do internado. Em segundo lugar, contrastando com esse ambiente rígido, apresenta-se um pequeno número de prêmios ou privilégios claramente definidos, obtidos em troca de obediência, em ação e espírito, à equipe dirigente. Em terceiro lugar, o elemento castigo está integrado no sistema de privilégios. Os castigos são definidos como conseqüências de desobediência às regras. Um conjunto de tais castigos é formado pela recusa ou retirada, temporária ou permanente, de privilégios, ou ainda pela eliminação do direito de adquiri-los.

Vamos enumerar e comentar a seguir alguns elementos do sistema de privilégios presentes no Ateneu. Havia um salão de estudos comum onde cada aluno possuía um espaço privativo pessoal:

Era a sala geral do estudo, à beira do pátio central, uma peça incomensurável, muito mais extensa do que larga. De uma das extremidades, quem não tivesse extraordinária vista custaria a reconhecer outra pessoa na extremidade oposta. À parede, em frente, perfilavam-se grandes armários com portas numeradas, correspondentes a compartimentos fundos: depósito de livros. Livros é o que menos se guardava em muitos compartimentos. $\mathrm{O}$ dono pregava um cadeado à portinha e formava $\mathrm{o}$ interior à vontade. (...) eu tive a idéia de armar em capela o compartimento do meu número (Pompéia, 1888/1997, p. 79).

Esse espaço privado onde se podem guardar coisas pessoais de modo inviolável é considerado por Goffman (1987, p. 204-208) como um direito que se perde numa instituição total. A posse de bens pessoais dificulta a eficiência institucional e os internados estão constantemente tentando garantir algum espaço onde possam manter bens pessoais a salvo dos demais, pois esses bens representam uma extensão do eu, e os 
"reservatórios" de bens pessoais representam sua autonomia.

Os dias de saída do colégio para os alunos eram quinzenais. Havia também saídas extraordinárias, concedidas como prêmio ou obséquio. Essas saídas eram obtidas através de um sistema de recompensas pelo bom desempenho escolar, que funcionava como o sistema de privilégios visando à reorganização subjetiva do indivíduo: a criança deveria se tornar um "aluno", personagem institucional, corpo dócil e disciplinado, submisso à autoridade escolar. $\mathrm{O}$ professor dava cartão amarelo ao aluno que fazia bem uma lição. Dez cartões desses valiam um cartão impresso, boa nota. Dez cartões de boa nota valiam um diploma que, por sua vez, tornava o aluno candidato a uma medalha de ouro ou de prata no final do curso. Pompéia (1888/1997, p. 97) avalia com ironia esse processo de recompensas, sem nenhum critério de justiça que o garanta. $\mathrm{O}$ cartão de boa nota podia ser usado para comprar uma saída extra. Sérgio nunca alcançava essas saídas de prêmio com seu mau desempenho escolar. Ainda havia um prêmio extraordinário para os alunos com excelente desempenho acadêmico: "Melhor que a prerrogativa do estudo era uma espécie de prêmio não catalogado nos estatutos, com que Aristarco gentilmente obsequiava os distintos. Levava-os a jantar em sua casa, uma honra!" (Pompéia, 1888/1997, p. 175).

Também podemos verificar funcionando no Ateneu aquilo que Goffman (1987, p. 54) denomina de sistema de ajustamentos secundários: operador constituído por práticas que não desafiam diretamente a equipe dirigente, mas permitem que os internados obtenham satisfações proibidas, ou consigam, por meios proibidos, as satisfações permitidas. Tais práticas surgem como uma reação do indivíduo que não se submete às mortificações infligidas à sua pessoa, e lhe dá uma prova clara de que ele ainda é um homem autônomo, cuja vontade não foi quebrada e que mantém um certo controle no seu ambiente. Os ajustamentos secundários se tornam verdadeiros nichos onde o indivíduo pode alojar e abrigar seu eu.

Os internados também criam algum tipo de código e meios de controle social informal para impedir que um deles informe a equipe dirigente quanto aos ajustamentos secundários de outros. Desse dispositivo de segurança, surge uma tipologia social: "dedo-duro", "ratos", "informantes", "espiões", "polícia secreta”, de um lado, e "boas-praças" de outro. Os internados que possuem fácil acesso a bens ilícitos disponíveis são outros tipos sociais, designando indivíduos poderosos no sistema de mercado informal. $O$ sistema de privilégios parece ser o principal esquema que, através de um modelo comportamental e condicionador, produz uma reorganização do indivíduo: o colégio não apenas fornece acesso à produção cultural social, mas seu funcionamento disciplinar visa produzir um indivíduo sujeitado. Seu treinamento físico, seu comportamento cotidiano, sua atitude moral, suas disposições, tudo é assumido pela educação no internato: educação total que através de uma modelagem microfísica busca uma produtiva recodificação da existência do indivíduo.

Pompéia comenta, de modo mais ou menos velado, como "a mocidade ia transigindo do melhor jeito com as bicudas imposições das circunstâncias" e que "as máximas, o diretor e a inspeção dos bedéis eram três espinhos" (Pompéia, 1888/1997, p. 99), comparando o ambiente colegial com um ouriço invertido.

Há outros elementos que podem ser considerados como parte do sistema de ajustamentos secundários, como, por exemplo, a solidariedade entre os internados: "não denunciar nunca é preceito sagrado de lealdade no colégio" (Pompéia, 1888/1997, p. 132). No caso dos cacos de vidro espalhados na piscina da natação (Pompéia, 1888/1997, p. 88), Sérgio mente para o diretor mas não consegue denunciar Franco. Quando Egbert fica envolvido no "caso Cândida", Sérgio sente-se solidário com ele e nunca toca no incidente desagradável com o amigo (Pompéia, 1888/1997, p. 173).

Exemplo de ajustamento secundário pode ser encontrado ainda no fato de os alunos maiores escaparem escondidos do dormitório coletivo para tomar a fresca no jardim do diretor, durante a noite:

\footnotetext{
Com o tempo vim a descobrir que uma camarilha de espertos conseguira sofismar alguns paus da grade da última janela, três ou quatro leitos além do meu, e passavam de noite, quando o silêncio se fazia, a tomar fresco no jardim do diretor. Preferiam as noites escuras, que têm mais estrelas e mais segredo, e preferiam as noites de chuva, que em questão de fresco são decisivas. Desciam por uma corda de lençóis torcidos e voltavam às vezes como pintos, mas refrescados sempre. Por medida de prudência, não passavam mais de dois por noite, fazendo sentinela um na ausência do outro (Pompéia, 1888/1997, p. 185-186).
}

Quando Sérgio descobre a esperteza e a ousadia dos colegas, sente-se incomodado com a liberdade secreta deles, sente-se roubado de um privilégio. 
Pensa em entregar todos ao Silvino, inspetor encarregado do dormitório dos grandes (Pompéia, 1888/1987, p. 182). Planejava

(...) trair merecidamente os traidores. Medi as objeções: além de feia delação de voluntário da espionagem, podia ser asneira. Talvez soubessem todos, menos eu, simplesmente por estar de pouco na terceira classe. Experimentei. Conservei-me acordado até a hora, com uma paciência e um esforço de caçador de emboscada. No momento flagrante, ergui-me na cama, esfregando os olhos, fingindo-me admirado. Não houve remédio senão iniciar-me. Os dois da noite contaram. O Malheiro era o chefe da troça, uma troça de nove, muito discretos, muito hábeis, também quem traísse apanhava. ...Sempre que por acaso algum rapaz surpreendia os expedicionários da frescata, era incontinenti aliciado para as vantagens e sob as ameaças (Pompéia,1888/1997, p. 186).

No Ateneu também havia mercado negro. Sérgio descreve com detalhes seu funcionamento:

Depois havia os jogos de parada, em que circulavam como preço as penas, os selos postais, os cigarros, o próprio dinheiro. As especulações moviam-se como o bem conhecido ofício das corretagens. Havia capitalistas e usurários, finórios e papalvos idiotas que se encarregavam de levar ao mercado com a facilidade de que dispunham fora do colégio, fornecimentos inteiros de Mallats e Guillots que os hábeis limpavam com a gentileza dos figurões da bolsa, e selos inestimáveis que os colecionadores desmereciam para tirar sem susto; fumantes ébrios de fumo alheio, adquirido facilmente no movimento da praça, repimpados à turca sobre os coxins da barata fartura. As transações eram proibidas pelo código do Ateneu. Razão demais para interessar. Da letra da lei, incubados sob a pressão do veto, surgiam outros jogos, mais expressamente característicos, dados que espirravam como pipocas, naipes em leque, que se abriam orgulhosos dos belos trunfos... roletas miúdas de cavalinhos de chumbo; uma aluvião de fichas em cartão, pululantes como os dados e coradas como os padrões do carteiro. A principal moeda era o selo. Pelo sinete da posta dava-se tudo. Não havia prêmios de lição que valessem o mais vulgar daqueles cupons servidos. Sobre este preço, permutavam-se os direitos do pão, da manteiga ao almoço, da sobremesa, as delícias secretas da nicotina, o próprio decoro pessoal de si. No comércio do selo é que fervia a agitação de empório, contratos de cobiça, de agiotagem, de esperteza, de fraude. Acumulavam-se valores, circulavam, frutificavam, conspiravam os sindicatos, arfava o fluxo, o refluxo das altas e das depreciações. Os inexpertos arruinavam-se, e havia banqueiros atilados, espapando banhas de prosperidade (Pompéia, 1888/1997, p. 132-135).

O "microcosmo de atividade subterrânea" reuniase no salão de estudos:

A sala geral do estudo, comprida, com as quatro galerias de carteiras e a parede oposta de estantes e a tribuna do inspetor, era um microcosmo de atividade subterrânea. Estudo era pretexto e aparência, as encadernações capeavam mais a esperteza do que os próprios volumes. A certas horas, reunia-se ali o colégio inteiro, desde os elementos de primeiras letras até os mais adiantados cursos. Agrupavam-se por ordem de habilitações; o abc diante da porta de entrada, à direita; à extrema esquerda, os filósofos, cogitadores do Barbe, os latinistas abalizados, os admiráveis estudantes do alemão e do grego. Baralhavam-se as três classes de idades... Dependia tudo do adiantamento (Pompéia, 1888/1997, p. 136).

Os alunos internados do Ateneu, para burlar a vigilância e se comunicarem, utilizavam

(...) os telégrafos e a correspondência de mão em mão. Os fios telegráficos eram da melhor linha de Alexandre 80, sutilíssimos e fortes, acomodados sob a tábua das carteiras, mantidas por alças de alfinete. Em férias desarmavam-se. Dois amigos interessados em comunicar-se estabeleciam o aparelho; a cada extremidade, um alfabeto em fita de papel e um ponteiro amarrado ao fio; legítimo Capanema. Tantas as linhas, que as carteiras vistas de baixo apresentavam a configuração agradável de cítaras encordoadas, tantas, que às vezes emaranhava-se $o$ serviço e desafinava a cítara dos recadinhos em harpa de carcamano (Pompéia, 1888/1997, p. 136).

O telégrafo escrito tinha uma desvantagem: não servia no escuro da noite. Para resolver o problema, inventaram o "telégrafo-martelinho. Tantas pancadinhas, tal letra; tantas mais tantas menos, tais outras" (Pompéia, 1888/1997, p. 137). Mas o inspetor encarregado da vigilância desconfiou dos ruídos que 
ouvia e destruiu, furioso, todo o equipamento dos garotos. "A violência não fez mais que aumentar o tráfego dos bilhetinhos e suspender temporariamente a telegrafia. De mão em mão como as epístolas, corriam os periódicos manuscritos e os romances proibidos" (Pompéia, 1888/1997, p. 137). Nestes periódicos, os alunos destilavam todo seu desprezo pelos colegas e autoridades do colégio. Os romances versavam sobre a luxúria e lutas pelo poder e dinheiro no mundo exterior.

Segundo Goffman (1987, p. 63-66), a vida no contexto institucional ainda produz alguns efeitos específicos no grupo dos internados. Efeitos que não estão previstos nos objetivos oficiais do estabelecimento e que acrescentam novos problemas para a equipe dirigente. Costumam surgir no grupo dos internados uma percepção particular do tempo, tal como nos mostra Sérgio:

O tédio é a grande enfermidade da escola, o tédio corruptor que tanto se pode gerar da monotonia do trabalho como da ociosidade. Tínhamos em torno da vida o ajardinamento em floresta do parque e a toalha esmeraldina do campo e o diorama acidentado das montanhas da Tijuca, ostentosas em curvatura toráxica e frentes felpudas de colosso; espetáculos de exceção, por momentos, que não modificavam a secura branca dos dias, enquadrados em pacote nos limites do pátio central, quente, insuportável de luz, ao fundo daquelas altíssimas paredes do Ateneu, claras da caiação, do tédio, claras, cada vez mais claras.Quando se aproximava o tempo das férias, o aborrecimento é maior. Os rapazes, em grande parte dotados de tendências animadoras para a vida prática forjavam mil meios de combater o enfado e a monotonia. A folgança fazia época como as modas, metamorfoseando-se depressa como uma série de ensaios (Pompéia, 1888/1997, p. 133).

Nesta vida reclusa, podemos constatar também o valor das distrações para os alunos internados:

A peteca não divertia mais, palmeada com estrépito, subindo como um foguete, caindo a rodopiar sobre o cocar de penas? Inventavam-se as bolas elásticas. Fartavam-se de borracha? Inventavam-se pequenas esferas de vidro. Acabavam-se as esferas? Vinham os jogos de salto sobre um tecido de linhas de giz no soalho, ou riscadas a prego na areia, a amarela, e toas as suas variantes, primeira casa, segunda casa, terceira casa, descanso, inferno, céu, levando-se à ponta de pé o seixozinho chato em arriscada viagem de pulos. Era depois a vez dos jogos de corrida, entre os quais figurava notavelmente o chicote-queimado. Variavam os aspectos da recreação, o pátio central animava-se com a revoada das penas, o estalar elástico das bolas, passando como obuses, ferindo o alvo em pontaria amestrada, o formigamento multicor das esferas de vidro pela terra, com a gritaria de todas as vozes do prazer e do alvoroço (Pompéia, 1888/1997, p. 133).

\section{O BODE EXPIATÓRIO: VÁLVULA DE ESCAPE DAS PRESSÕES INSTITUCIONAIS}

Como todo sistema que vive oscilando à beira do desequilíbrio, o Ateneu também tem suas válvulas de escape. A figura agoniada de Franco, o rebelde permanentemente castigado e igualmente reincidente, é um exemplo de bode expiatório, no qual todos exorcizam a má consciência que os aguilhoa em meio a tantas contradições. Já no primeiro dia de aula, Franco estava de castigo, ajoelhado no chão (Pompéia, 1888/1997, p. 53). Rebelo comentou com Sérgio:

'Se [Franco] não tivesse calos no joelho, não haveria canto do Ateneu que ele não marcasse com o sangue de uma penitência. $\mathrm{O}$ pai é do Mato Grosso; mandou-o para aqui com uma carta em que recomendava como incorrigível, pedindo severidade. O correspondente envia de tempos a tempos um caixeiro que faz os pagamentos e deixa lembranças. Não sai nunca (...)' (Pompéia, $1888 / 1997$, p. 54).

[O Franco] sempre de penitência; em pé, cara contra a parede. Como Silvino dava-lhe as costas, divertia-se a pegar moscas para arrancar a cabeça e ver morrer o bichinho na palma da mão. Perguntei-lhe por que estava de castigo. Sem olhar, de mau modo: 'Lá sei! disse ele. Porque me mandaram'. E continuou a pegar moscas. Franco era um rapazola de quatorze anos, raquítico, de olhos pasmados, face lívida, pálpebras pisadas. À fronte, com a expressão vaga dos olhos e obliqüidade dolorida dos supercílios, pousava uma névoa de aflição e paciência, como se vê no Flos Sanctorum. A parte inferior do semblante rebelava-se; um canto dos lábios franzia-se em contração constante de odiento desprezo. Franco não ria nunca. Sorria apenas, assistindo a uma briga séria. Interessando-se pelo desenlace como um apostador de rinha, enfurencendo-o quando apartavam. Uma queda alegrava-o, 
principalmente perigosa... (Pompéia,1888/ 1997, p. 56).

Como os criminosos, os loucos e as prostitutas que são apontados e condenados pela repulsa geral, procurando de algum modo esconjurar as tentações de ódio e perversão que assediam as almas de todos, Franco era escarmentado pelo colégio em peso:

(...) Vivia isolado no círculo da excomunhão com que o diretor, invariavelmente, o fulminava todas as manhãs, lendo no refeitório perante o colégio as notas da véspera. Os professores já sabiam. À nota do Franco, sempre má, devia seguir-se especial comentário deprimente, que a opinião esperava e ouvia com delícia, fartando-se de desprezar. Nenhum de nós como ele! E o zelo do mestre cada dia retemperava o velho anátema. Não convinha expulsar. Uma coisa destas aproveita-se como um bibelô do ensino intuitivo, explora-se como a miséria do ilota, para a lição fecunda do asco. A própria indiferença da vítima é útil. Três anos havia que o infeliz, num suplício de pequeninas humilhações cruéis, agachado, abatido, esmagado, sob o peso das virtudes alheias mais que das próprias culpas, ali estava, - cariátide forçada no edifício de moralização do Ateneu, exemplar perfeito da depravação oferecido ao horror santo dos puros (...) 'Nenhum de nós como ele' - é o alívio dos alunos reunidos à hora em que se lêem os boletins de notas (Pompéia, 1888/1997, p. 56).

Deixar-se morrer doente e preso na cafua foi alternativa que Franco encontrou para se vingar de todos e assim, alcançar a liberdade. A estratégia de intransigência (Goffman, 1987, p. 60) de Franco, através da qual desafiava intencionalmente a instituição, negando-se de modo visível a cooperar com os dirigentes, produziu como efeito direto o zelo especial do diretor e de sua equipe para com o rebelde.

\section{O MUNDO DA EQUIPE DIRIGENTE}

O diretor foi descrito de modo caricaturesco por Pompéia/Sérgio, realçando seus traços negativos. Aristarco, tipo consumado do empresário da educação, mestre na arte da pose e da autopromoção, vendia uma imagem idealizada do seu negócio:

Nas ocasiões de aparato é que se podia tomar pulso ao homem. Não só as condecorações gritavam-lhe do peito como uma couraça de grilos: Ateneu! Ateneu! Aristarco era todo um anúncio. Os gestos, calmos, soberanos, eram de um rei - o autocrata excelso dos silabários, a pausa hierática do andar deixava sentir o esforço, a cada passo, que ele fazia para levar adiante, de empurrão, o progresso do ensino público(...) (Pompéia, 1888/1997, p. 33).

Nos eventos públicos, exibições institucionais (Goffman, 1987, p. 90ss.) que funcionavam como publicidade do estabelecimento, "Aristarco arrebentava de júbilo... distribuía-se numa ubiqüidade impossível de meio ambiente ..." deslocando-se por toda parte e falando com todos (Pompéia, 1888/1997, p. 39-40).

Ele interrompia sua atividade de contador para receber os alunos que chegavam, dissimulando o empresário por trás da máscara do educador:

O diretor, no escritório do estabelecimento, ocupava uma cadeira rotativa junto à mesa de trabalho. Sobre a mesa, um grande livro abria-se em colunas maciças de escrituração e linhas encarnadas. Aristarco, que consagrava as manhãs ao governo financeiro do colégio, conferia, analisava os assentamentos do guarda-livros (...) (Pompéia, 1888/1997, p. 45).

A substância do diretor se encontrava na ostentação de si mesmo e na sede de lucro, pois o dinheiro era o absoluto da vida burguesa. Aristarco graduava os olhares, os sorrisos, as predileções no sistema de chefia, e até mesmo a escolha do futuro genro, pelos critérios de guarda-livros como pontualidade no pagamento das mensalidades: “... Às vezes, uma criança sentia uma alfinetada no jeito da mão a beijar. Saía indagando consigo o motivo daquilo, que não achava em suas contas escolares... O pai estava dois trimestres atrasado" (Pompéia, 1888/1997, p. 46).

Aristarco não era apenas o supervisor do seu colégio, ele era de fato um símbolo da administração e de todo o estabelecimento (Goffman, 1987, p. 96). Ele se apresenta como uma figura do patriarcalismo, ícone de um regime paternalista em que o senhor de engenho e o dono de estância são substituídos por um diretor de colégio.

Não admira que em dias de gala, íntima ou nacional, festas do colégio ou recepção da coroa, o largo peito do grande educador desaparecesse sob constelações de pedraria, opulentando a nobreza de todos os honoríficos berloques (Pompéia, 1888/1997, p. 32). 
Nas cerimônias institucionais (Goffman, 1987, p. 84ss.), o diretor se vestia bem, ficava comovido com a cerimônia, sorria, fazia discursos, dava parabéns, julgava as disputas, distribuía prêmios. Nessa atuação, desempenhava uma interação benigna e demonstrava interesse paternal para com os alunos e estes mostravam acanhamento, deferência e respeito. Isso é muito parecido com a representação de um senhor feudal desempenhando seu papel na festa anual em seu feudo, em plena sociedade moderna. "Ator profundo, realizava ao pé da letra, a valer, o papel diáfano, sutil, metafísico, de alma da festa e alma do seu instituto" (Pompéia, 1888/1997, p. 40).

O diretor se arvora de guia e senhor. E recebe o reconhecimento dos demais. Há no colégio um estranho processo de entetização. Todos parecem acatar não apenas uma posição subalterna, mas sobretudo infamante. Portam-se como coisas, como animais em relação àquele que os une, que os mantém, que os maltrata. Não são apenas vítimas, logo metamorfoseiam-se em cúmplices. (...) Aristarco é o Ateneu (Nunes, 1980, p. 225).

Aristarco mantinha uma vigilância ostensiva sobre a vida dos internados, com traços maquiavélicos: dominava pelo terror de aparições súbitas e inadvertidas que fazia nos vários ambientes do colégio, salas de estudo, de aula, surpreendendo professores e alunos, procurando flagrantes.

(...) Por meio deste processo de vigilância de inopinados, mantinha no estabelecimento por toda parte o risco perpétuo do flagrante com uma atmosfera de susto. Fazia mais com isso que a espionagem de todos os bedéis. Chegava o capricho a ponto de deixar algumas janelas ou portas como votadas a fechamento para sempre, com o fim único de um belo dia abri-las bruscamente sobre qualquer maquinação clandestina da vadiagem. Sorria então no íntimo, do efeito pavoroso das armadilhas, e cofiava os majestosos bigodes brancos de marechal, pausadamente, como lambe o jaguar ao focinho a pregustação de um repasto de sangue (Pompéia, 1888/1997, p. 83-84).

Auxiliando o diretor no cuidado da disciplina dos alunos no Ateneu, estavam os inspetores. João Numa, inspetor ou bedel, tratou Sérgio com delicadeza, quando ele era um novato no colégio (Pompéia, 1888/1997, p. 49). O inspetor Silvino "fiscalizava o recreio, graduando a folgança, à mercê de um terrível canhenho. Sentava-se à entrada do portão do lavatório" (Pompéia, 1888/1997, p. 55). Um inspetor vigiava o banho, "com a varinha destinada aos retardatários", mas ficava afastado e não via os abusos dos marmanjos com relação aos menores (Pompéia, $1888 / 1997$, p. 60). Inspetores vigiavam também as salas de aula (Pompéia, 1888/1997, p. 68). Os inspetores vigiavam a distribuição da merenda, "prevenindo as espertezas inconvenientes" (Pompéia, $1888 / 1997$, p. 85), mas não observavam os maustratos dos colegas com relação a Franco, o bode expiatório do estabelecimento. Mais tarde, os inspetores comentariam com o diretor sobre a decadência de Sérgio e de sua proximidade com Franco (Pompéia, 1888/1997, p. 86). “O policiamento dos dormitórios competia aos diversos inspetores, convenientemente distribuídos" (Pompéia, 1888/1997, p. 139) Geralmente, os inspetores temiam os maiores e os deixavam em paz (Pompéia, 1888/1997, p. 182).

Quanto aos horários e rotinas diárias no Ateneu, se despertava às cinco horas da manhã (Pompéia, 1888/1997, p. 58). Nas épocas de maior calor, havia dois banhos por dia, na piscina da natação (Pompéia, 1888/1997, p. 59). A disciplina determinava a divisão dos banhistas em três turmas, conforme as idades. Mas as turmas se misturavam, devido à falha na vigilância do inspetor de plantão, “(...) de sorte que ficavam expostos os mais fracos aos abusos dos marmanjos..." (Pompéia, 1888/1997, p. 60). Verificamos na descrição do banho comum que era oferecido aos internados, um exemplo de exposição contaminadora. De acordo com Goffman (1987, p. 31), elas podem ser físicas, sociais e psicológicas (apelidos, gozações), onde as fronteiras que o indivíduo estabelece entre seu ser e o ambiente são invadidas e sua pessoa pode ser sistematicamente profanada. Já não pode mais, como no mundo externo, manter objetos investidos por seu eu (seu corpo, suas ações imediatas, seus pensamentos e alguns de seus bens) fora de contato com coisas estranhas e contaminadoras. A vida em grupo exige contato mútuo e permanente exposição entre os internados.

(...) e cada banho era uma festa, naquela água gorda, salobra da transpiração das turmas precedentes, que as dimensões do tanque impediam a devida renovação; turbulento debate de corpos nus, estreitamente cingidos no calção de malha rajado a cores, enleandose os rapazes como lampreias (...) os menores agrupados no raso, dando-se as mãos em cacho, espavoridos, se algum mais forte chegava (Pompéia, 1997, p. 59).

Ao meio-dia, Aristarco aproveitava a reunião de todos para a refeição e distribuía conselhos, 
advertências e reprimendas em massa por culpas coletivas. Realizava arrecadações de cigarros e também pequenos processos sumários nos quais averiguava a autoria de delitos importantes, tais como: encher de papel picado uma sala, cuspir nas paredes, molhar a privada e outros mais graves. (Pompéia, 1888/1997, p. 83). Havia orações especiais em devoção à Virgem Maria no mês de maio (Pompéia, 1888/1997, p. 80). Rezava-se o "hino do anjo da guarda" ao meio-dia (Pompéia, 1888/1997, p. 81) e havia a oração da noite, aborrecida pelos meninos, exaustos do desgaste do dia (Pompéia, 1888/1997, p. 82).

\begin{abstract}
Os exercícios corporais efetuavam-se à tarde, uma hora depois do jantar, hora excelente, que habituava a digestão a segurar-se no estômago e não escorrer pela goela quando os estudantes se balançavam à barra-fixa, pelas curvas... Findos os exercícios, partia o professor Bataillard, e, guardados por dois inspetores, o Silvino e o João Numa, ou João Numa e o velho Margal, venerando inválido espanhol, querido de todos, ou o Margal e o Conselheiro, tínhamos os alunos, um prazo de recreio até o cair da noite (Pompéia, $1888 / 1997$, p. 69).
\end{abstract}

Todas as atividades cotidianas eram prescritas pelo regulamento da casa. A vida dos alunos internados no Ateneu era governada por normas e regulamentos que previam prêmios e castigos, escritos em grandes quadros, espalhados pelas paredes do colégio (Pompéia, 1888/1997, p. 48). Segundo Foucault (1975/1999b, p. 151ss) e Goffman (1987, p. 49-58), existe um sistema de gratificação-sanção nas instituições totais, que realiza uma contabilidade penal, qualificando comportamentos e desempenhos a partir de dois valores opostos do bem e do mal, produzindo uma microeconomia dos privilégios e castigos. "... Todas as culpas são prevenidas, uma pena para cada hipótese...", diz Aristarco para Sérgio e seu pai, no dia do ingresso no Ateneu (Pompéia, 1888/1997, p. 48). Mas ali “(...) não havia expressamente punições corporais" (Pompéia, 1888/1997, p. 76). Visibilidade total e irrestrita é a nova estratégia utilizada pelo poder disciplinar para realizar o controle - sem uso da violência ostensiva para o exercício de uma vigilância produtiva. Cria-se um operador, "observatório" que obriga pelo jogo do olhar, um aparelho no qual técnicas óticas efetuam manobras de poder: olho do poder que vigia, produz, torna inteiramente visíveis os indivíduos sobre os quais incide (Foucault, 1975/1999b).
O colégio funcionava dentro de uma verdadeira organização militar, na qual trezentos alunos internos eram repartidos em grupos de trinta, sob o comando direto de um vigilante, aluno do colégio. Os vigilantes eram escolhidos pelo diretor entre os alunos internos por seleção de aristocracia.

Esses inferiores da milícia da casa faziam-se tiranetes por delegação da suprema ditadura. Armados de sabres de pau com guardas de couro, tomavam a sério a investidura do mando e eram em geral de uma ferocidade adorável. Os sabres puniam sumariamente as infrações da disciplina na forma: duas palavras ao cerra-fila, perna frouxa, desvio notável do alinhamento. Regime siberiano, como se vê, do que resultava que os vigilantes eram altamente conceituados (Pompéia, 1888/1997, p. 61-62).

Podemos ver no comportamento tirânico dos alunos vigilantes um claro exemplo do mecanismo da tiranização, incluindo a autoridade escalonada: qualquer pessoa da equipe dirigente tem o direito de impor disciplina a qualquer dos internados, o que aumenta claramente a possibilidade de sanção (Goffman, 1987, p. 45), produzindo um clima decididamente aterrorizante e persecutório para os alunos.

\section{O MICROTRIBUNAL PEDAGógICO}

Consideramos que um importante operador microfísico do Ateneu, instrumento de poder altamente mortificador, era o livro de notas. Toda a manhã, Aristarco abria um livro no qual os professores haviam feito anotações relativas ao aproveitamento dos alunos. Ele lia as notas e praticava assim uma clara violação de reserva de informações da vida escolar de cada aluno diante de toda a comunidade. Do livro aberto, se construía e se destruía sem pruridos a reputação dos alunos.

(...) Os vitimados fugiam, acabrunhados de vergonha, oprimidos sob o castigo incalculável de trezentas carinhas de ironia superior ou compaixão de ultraje. Passavam junto de Aristarco ao sair para a tarefa penal de escrita. O diretor, arrepiando uma das cóleras olímpicas que de um momento para outro sabia fabricar, descarregava com o livro às costas do condenado, agravante de injúria e escárnio à pena de difamação. $\mathrm{O}$ desgraçado sumia-se no corredor, cambaleando (Pompéia, 1888/1997, p. 75). 
Essa prática marcava de tal modo o indivíduo com um estigma de incapacidade, que acabava, por contágio de convicção, reforçando a imagem negativa do internado na opinião dos companheiros. O resultado era o da profecia auto-realizada, que se consumava quando o próprio indivíduo se convencia de sua inépcia e achava justa a condenação. Evidentemente a leitura cotidiana do livro de notas funciona como o "circuito" (Goffman 1987, p. 40) e como vigilância, exame e sanção normalizadora (Foucault, 1975/1999b). Podemos falar de uma "terapeutização da pedagogia" com finalidade normatizante e normalizadora.

Goffman (1987, p. 40) descreve o circuito como uma perturbação na relação usual entre $\mathrm{o}$ ator individual e seus atos. Uma agência cria uma resposta defensiva no internado e depois utiliza essa resposta para seu ataque seguinte. $\mathrm{O}$ indivíduo descobre que sua resposta protetora diante de um ataque à sua pessoa falha na situação, pois não pode defender-se da forma usual ao tentar estabelecer uma distância entre a situação mortificante e seu ego. Como as esferas da vida estão interligadas no contexto institucional, a conduta do internado numa área de atividade é lançada contra ele pelos dirigentes, como comentário e verificação de sua conduta em outro contexto. O "circuito" inclui a tiranização (Goffman, 1987, p. 41) do indivíduo através de um processo de infantilização social que retira da pessoa sua autonomia, liberdade de ação e capacidade de decisão, perturbando decididamente sua autonomia civil; a obrigação de pedir permissão ou instrumentos para realizar atividades secundárias que o indivíduo pode executar sozinho no mundo externo, produz submissão e infantilização; o processo de arregimentação (Goffman, 1987, p. 44) indica a obrigação de executar a atividade regulada em uníssono com grupos de outros internados e ainda um sistema de autoridade escalonada no qual qualquer pessoa da equipe dirigente tem o direito de impor disciplina a qualquer dos internados, o que aumenta claramente a possibilidade de sanção.

Com exceção dos privilegiados, os vigilantes, os amigos do peito, os que dormiam à sombra de uma reputação habilmente arranjada por um justo conchavo de trabalho e cativante doçura, havia para todos uma expectativa de terror antes da leitura das notas. O livro era um mistério (Pompéia,1888/1997, p. 75).

A leitura matinal do livro de notas se assemelhava a um processo judicial que apresentava e denunciava culpados, fustigando-os com o vexame da humilhação pública, e o juiz implacável, encarnado pelo diretor, sentenciava o faltoso imediatamente. A tecnologia disciplinar do livro de notas ensinava os internados a viverem sob condições de exposição iminente, sujeitos a grandes flutuações de consideração, com pouco controle da obtenção ou perda de tal consideração, sendo esta uma etapa importante na carreira moral e na socialização dos internados. $\mathrm{O}$ fato de ter seu desempenho acadêmico elevado à categoria máxima e definidora de sua pessoa, seu fracasso ou sucesso escolar submetido a constante monitoração e avaliação moral, impede que o indivíduo conserve opiniões firmes a respeito de seu autoconceito.

$\mathrm{O}$ internado aprende que as degradações e reconstruções do eu não devem ser muito consideradas, e ao mesmo tempo aprende que a equipe dirigente e os outros internados estão preparados para interpretar, com certa indiferença, as destruições e reconstruções do eu. Aprende que uma imagem defensável do eu pode ser vista como algo fora de si mesmo e que pode ser construída, perdida e reconstruída - tudo isso com certa rapidez e justiça (Goffman, 1987, p. 139-140).

Esse contexto moral, pouco sério e exagerado, no qual a construção do autoconceito e sua destruição eram transformadas num jogo indiscreto e impudico, produzia no internado uma desmoralização, ao ensinar-lhe a viver esse processo de forma incessante. $\mathrm{O}$ fato de que o eu do indivíduo fosse tratado como uma cidade aberta e não como uma fortaleza particular e inviolável, produzia uma fadiga e um relaxamento moral. $\mathrm{O}$ internado aprendia que podia sobreviver e agir de uma forma que a instituição considera negativa. Sérgio nos oferece um exemplo disso com sua prostração e impotência nas quais se abandonou (Pompéia, 1888/1997, p. 77ss). Não importava quão baixo ele estivesse na escala das considerações institucionais - como era o caso de Franco, de um modo mais radical - isso não era capaz de excluí-lo da comunidade dos internados. Ao aceitar a interpretação institucional a seu respeito, o indivíduo podia adquirir a intenção de emendar-se, corrigir-se e solicitar da equipe dirigente auxílio, compreensão, privilégios e perdão, com o objetivo de perseverar nessa nova atitude. Mas não foi isso o que aconteceu com Sérgio nesse momento, ele vivia uma temporada de intenso fervor religioso (Pompéia, 1888/1997, p. 93) e, depois de rebelar-se contra a tirania dos vigilantes, passou a utilizar a estratégia da "viração": trata-se de uma combinação oportunista de ajustamentos secundários, conversão, colonização e lealdade aos colegas, de 
modo a obter, dentro da situação específica, uma possibilidade máxima de evitar sofrimentos físicos ou psicológicos (Pompéia, 1888/1997, p. 98).

Cada carreira moral, e, atrás desta, cada eu, se desenvolve dentro dos limites de um sistema institucional, seja um estabelecimento social, seja um complexo de relações pessoais e profissionais. Portanto, o eu pode ser visto como algo que se insere nas disposições que um sistema social estabelece para seus participantes. Nesse sentido, o eu não é uma propriedade da pessoa a que é atribuído, mas reside no padrão de controle social que é exercido pela pessoa e por aqueles que a cercam. Pode-se dizer que esse tipo de disposição social não apenas apóia, mas constitui o eu (Goffman, 1987, p. 142).

Geralmente as pessoas exigem proteção e aceitação tácita para a versão de si mesmas que apresentam aos demais. $\mathrm{O}$ afastamento dessa proteção do autoconceito forma um aspecto sistemático e intencional no funcionamento do Ateneu, cristalizado no livro de notas que o diretor lia a cada manhã perante a comunidade escolar.

\section{O MICROTRIBUNAL INQUISITORIAL}

No Ateneu realizou-se um processo inquisitorial, que denominamos de "caso Cândida". Toda a comunidade escolar ficou em polvorosa diante da ameaça que pairava sobre todos, gerando um clima altamente persecutório. Um dos alunos, Cândido, havia enviado uma carta de amor para um colega e assinado "Cândida".

Aristarco discursou e trovejou sobre a comunidade escolar na hora do jantar: 'Tenho a alma triste, Senhores! A imoralidade entrou nesta casa! Recusei-me a dar crédito, rendi-me à evidência...' Com todo o vigor tenebroso dos quadros trágicos, historiou-nos uma aventura brejeira. Uma carta cômica e um encontro marcado no jardim. 'Ah! Mas nada me escapa... tenho cem olhos. Se são capazes, iludam-me! Está em meu poder um papel, monstruoso corpo de delito! Assinado por um nome de mulher! Há mulheres no Ateneu, meus senhores! Esta mulher, esta cortesã fala-nos da segurança do lugar, do sossego do bosque, da solidão a dois... um poema de pouca vergonha! É muito grave o que tenho a fazer. Amanhã é o dia da justiça! Apresento-me agora para dizer somente: serei inexorável, formidando! E para prevenir: todo aquele que direta ou indiretamente se acha envolvido nessa miséria... tenho a lista dos comprometidos... e que negar espontâneo auxílio ao procedimento da justiça, será reputado cúmplice e como tal: punido!' Este convite era um verdadeiro arrastão. Remexendo a gaveta da consciência e da memória, ninguém havia, pode-se afirmar, que não estivesse implicado na comédia colegial dos sexos, ao menos pelo enredo remoto do ouvi dizer. Ouvir dizer e não denunciar logo era um crime dos grandes na jurisprudência costumeira. A devassa prometida fazia alarma geral. Como prever as complicações do processo? Como adivinhar o segredo tremendo da lista? Aristarco ufanava-se de perspicácia de inquisidor. Sob a saraivada das perguntas, ameaças, promessas, o interrogado perturbava-se, comprometia-se, entregava-se e traía os outros; nos processos de gabinete, os fatos floresciam em corimbo, frutificavam em cacho; a pesquisa de uma culpa descobria três, sem contar as ramificações da cumplicidade de outiva. Ao retirar-se, o diretor deixou na sala uma estupefação de pavor (Pompéia, 1888/1997, p. 161).

Sérgio também temeu e se sobressaltou, pois suas relações pessoais com o diretor já eram complicadas e se agravaram ainda mais a partir de um incidente que ocorreu entre ambos, logo depois de uma luta do menino com seu protetor e quase namorado Bento Alves (Pompéia, 1888/1997, p. 162-163). Sua persecutoriedade não era infundada. Sérgio relatou com detalhes a sessão solene do processo:

Não foi possível dormir tranqüilo. À hora do primeiro almoço, como prometera, Aristarco mostrou-se em toda sua grandeza fúnebre dos justiçadores. De preto. Calculando magnificamente os passos pelos do diretor, seguiam-no em guarda de honra muitos professores. À porta fronteira, mais professores de pé e os bedéis ainda, e a multidão bisbilhoteira dos criados. Tão grande a calada, que se distinguia nítido o tique-taque do relógio, na sala de espera, palpitando os ansiados segundos. Aristarco soprou duas vezes através do bigode, inundando o espaço com um bafejo todopoderoso. E sem exórdio: 'Levante-se, Sr. Cândido Lima! Apresento-lhe, meus senhores, a Sr ${ }^{\mathrm{a}}$. D. Cândida', acrescentou com uma ironia desanimada. Para o meio da casa! E curve-se diante dos seus colegas!' Cândido era um grande menino, beiçudo, louro, de olhos verdes e maneiras difíceis de 
indolência e enfado. Atravessou devagar a sala, dobrando a cabeça, cobrindo o rosto com a manga, castigado pela curiosidade pública. 'Levante-se, Sr. Emílio Tourinho...' Tourinho era um pouco mais velho do que o outro, porém mais baixo; atarracado, moreno, ventas arregaladas, sobrancelhas crespas, fazendo um só arco pela testa. Nada absolutamente conformado para um galã; mas era com efeito o amante. 'Venha ajoelhar-se com o companheiro. Agora, os auxiliares...' Desde as cinco horas da manhã trabalhava Aristarco no processo. O interrogatório, com o apêndice das delações da polícia secreta e dos tímidos, comprometera apenas dez alunos. À chamada do diretor, foram deixando os lugares e postando-se de joelhos em seguimento dos principais culpados. 'Estes são os acólitos da vergonha, os co-réus do silêncio!' Cândido e Tourinho, braço dobrado contra os olhos, espreitavam-se a furto, confortando-se na identidade da desgraça, como Francesca e Paolo no inferno. Prostrados os doze rapazes perante Aristarco, na passagem alongada entre as cabeceiras das mesas, parecia aquilo um ritual desconhecido de noivado: à espera de benção para o casal à frente. Em vez de benção chovia a cólera. 'Esquecem pais e irmãos, o futuro que os espera, e a vigilância inelutável de Deus!... Na face estranhada não lhes pegou o beijo das mães... caiu-lhes a vergonha como um esmalte postiço... Deformada a fisionomia, abatida a dignidade, agravam ainda a natureza; esquecem as leis sagradas do respeito à individualidade humana... E encontram colegas assaz perversos, que os favorecem, calando a reprovação, furtando-se a encaminhar a vingança da moralidade e a obra restauradora de justiça!...' O diretor derramou toda sua fúria sobre os pobres condenados. Depois, "conduzidos pelos inspetores, saíram os doze como uma leva de convictos para o gabinete do diretor, onde deviam ser literalmente seviciados, segundo a praxe da justiça do arbítrio. Consta que houve mesmo pancada de rijo. Os condenados negaram, depois. Em todo caso, era de efeito o simples consta, engrandecido pela refração nebulosa do boato. Concluída a chamada dos indiciados, a sala inteira respirou desafogo. No recreio, a rapaziada dispersou-se com gritos festivos (Pompéia, 1888/1997, p. 164-166).

Vemos assim como funciona no Ateneu um "mecanismo penal" de efeitos microfísicos: uma máquina kafkiana de punir que "é beneficiada por uma espécie de privilégio de justiça, com suas leis próprias, suas instâncias de julgamento, estabelecendo infrapenalidades" (Foucault, 1975/1999b, p. 149).

\section{CONCLUSÃO: O INTERNATO ESCOLAR COMO UMA INSTITUIÇÃO FORMATIVA, EDUCATIVA E TERAPÊUTICA}

O “Ateneu" é uma instituição pedagógica que possui aspectos de um sistema correcional, exercendo as funções de reclusão e de custódia, Funciona de modo sutil, objetivando a modelagem da subjetividade dos seus membros internados, no que ele se assemelha com a prisão. Acolhe o aluno em sua clausura, confinando-o para formá-lo no contexto institucional.

A educação acadêmica se apresenta como o objetivo oficial do Ateneu. Mas o estabelecimento exerce uma função de atenção aos alunos, membros residentes na instituição, oferecendo mais e menos do que apenas escolarização. É nesse ambiente inclusivo que suas necessidades biológicas, psíquicas e sociais devem ser satisfeitas. O Ateneu também produz mudanças psicológicas no internado, especificando-as e estabelecendo operadores institucionais adequados para consegui-las.

Entendemos que o Ateneu, enquanto estabelecimento, constitui-se num bloco de condições materiais objetivas: sua organização espacial, o regulamento meticuloso que rege sua vida interior, as várias atividades aí desenvolvidas, os diversos personagens que aí vivem e se encontram, cada um com uma função, um lugar, etc. Ali as relações de comunicação e de poder são produtoras de uma subjetividade específica. Acreditamos que a atividade que assegura o aprendizado e a aquisição de aptidões ou tipos de comportamento aí se desenvolve através de um conjunto de comunicações reguladas: aulas, perguntas e respostas, ordens, exortações, signos codificados de obediência, marcas distintivas do valor de cada um e dos níveis de saber; e através de uma série de procedimentos de poder: enclausuramento, vigilância, exame, recompensa e punição, hierarquia piramidal. Como todo espaço institucional fechado, o Ateneu provavelmente funciona a partir de dois elementos essenciais: o aparelho, constituído pelo próprio estabelecimento, e regras (explícitas e implícitas).

Em termos de efeitos éticos, a experiência de internação numa instituição total produz resultados muito distantes dos objetivos oficiais que costumam constar em seus estatutos e regimentos (Benelli, 2002; Benelli \& Costa-Rosa, 2003). Ela parece, normalmente, produzir efeitos contrários aos 
prometidos. Em suas conclusões, Goffman (1987, p. 246) afirma que:

Sempre que estudamos um estabelecimento social, verificamos uma discrepância com esse primeiro tema: verificamos que os participantes se recusam, de alguma forma, a aceitar a interpretação oficial do que devem dar e retirar da organização, e, além disso, quanto ao tipo de eu e de que mundo que devem aceitar para si mesmos. Onde se espera entusiasmo, haverá apatia; onde se espera afeição, há indiferença; onde se espera freqüência, há faltas; onde se espera robustez, há algum tipo de doença; onde as tarefas devem ser realizadas, há diferentes formas de inatividade. Encontramos inúmeras histórias comuns, cada uma das quais é, a seu modo, um movimento de liberdade. Sempre que se impõem mundos, se criam submundos.

As instituições totais tendem a ser (re)produtoras de indivíduos normalizados, modelados numa subjetividade serializada. O Ateneu é um bom exemplar da implementação do dispositivo pedagógico com seus diversos operadores, tal como vemos emergir em Foucault (1975/1999b): escolarização disciplinar produzindo efeitos normalizadores. O seu núcleo subjetivizante estaria centrado numa formação disciplinar ao mesmo tempo moral e psicológica. A ação institucional incide normativamente sobre as condutas. A subjetividade produzida neste contexto seria caracterizada por traços essencialmente normatizados/normatizadores, através de um jogo de forças (ativas e reativas) que visam à normatização da conduta do outro.

\section{REFERÊNCIAS}

Benelli, S. J. (2002). O internato escolar como instituição total: violência e subjetividade. Psicologia em Estudo. 2 (7), 1929.

Benelli, S. J. \& Costa-Rosa, A.(2002) A produção da subjetividade no contexto institucional de um seminário católico. Estudos de Psicologia. 2 (19), 37-58.

Benelli, S. J. \& Costa-Rosa, A.(2003) Geografia do poder em Goffman: vigilância e resistência, dominação e produção de subjetividade no hospital psiquiátrico. Estudos de Psicologia. 2 (20), 35-49.

Foucault, M. (1982). História da sexualidade I: a vontade de saber. (M. T. C. Albuquerque, Trad.) Rio de Janeiro: Graal.

Foucault, M. (1984). A verdade e as formas jurídicas. (R. C. M. Machado, E. J. Morais Trad.) Rio de Janeiro: PUC.

Foucault, M. (1999a). História da loucura na Idade Clássica. (J. T. C. Neto, Trad.) São Paulo: Perspectiva. (Originalmente publicado em 1972).

Foucault, M. (1999b). Vigiar e punir: nascimento da prisão. (R. Ramalhete, Trad.) Petrópolis: Vozes. (Originalmente publicado em 1975).

Freitag, B. (2001). O indivíduo em formação: diálogos interdisciplinares sobre educação. São Paulo: Cortez.

Goffman, E. (1987). Manicômios, prisões e conventos. (D. M. Leite, Trad.) São Paulo: Perspectiva. (Originalmente publicado em 1961).

Nunes, A. C. (1980). Sociedade e poder no 'Ateneu' de Raul Pompéia. Revista do Instituto de Filosofia e Ciências Humanas - UFRGS. 8, 221-231.

Perrone-Moisés, L. (Org.) (1988). O Ateneu: retórica e paixão. São Paulo: Brasiliense/EDUPS.

Pompéia, R. (1997). O Ateneu. São Paulo: Publifolha. (Originalmente publicado em 1888).

Recebido em 16/06/2003

Aceito em 24/11/2003

Endereço para correspondência: Sílvio José Benelli, Rua José Bonifácio, 1185, apto. 41, Bairro Jardim Cristo Rei, CEP 17513230, Marília-São Paulo. E-mail: sjbewelli@yahoo.com.br 